\title{
Acacia senegal gum exudate offers protection against cyclophosphamide-induced urinary bladder cytotoxicity
}

\author{
Abdulaziz A. Al-Yahya, ${ }^{1}$ Abdulhakeem A. Al-Majed, ${ }^{1}$ Ali M. Gado, ${ }^{1}$ Mohammad H. Daba, ${ }^{1}$ Othman A. Al-Shabanah, ${ }^{1}$ \\ Adel S. El-Azab² and Adel R.A. Abd-Allah ${ }^{1, *}$ \\ 'Department of Pharmacology; ${ }^{2}$ Department of Pharmaceutical Chemistry; College of Pharmacy; King Saud University; Riyadh, Saudi Arabia
}

Key words: gum arabic, cyclophosphamide, acrolein, lipid peroxidation, bladder inflammation, oxidative stress

Cylophosphamide (CYCL) is a strong anticancer and immunosuppressive agent but its urotoxicity presents one of the major toxic effects that limit its wide usage particularly in high dose regimens. Therefore, this study aimed to investigate Acacia Senegal gum exudate, Gum Arabic (GA), for its possible role as a natural, nontoxic agent against CYCL-induced urotoxicity. Male Swiss albino rats were exposed to CYCL $(150 \mathrm{mg} / \mathrm{kg} \mathrm{BW}$, once i.p) with or without GA oral supplementation $(7.5 \mathrm{~g} / \mathrm{kg} /$ day for 6 days) through drinking water. Glutathione (GSH), Malondialdehyde (MDA) and Nitric oxide (NO) bladder contents were assessed. Responsiveness of the bladder rings to acetylcholine $(\mathrm{ACh})$ in vitro, microscopic and macroscopic features are also investigated. CYCL produced pronounced harmful effects on bladder urothelial lining with significant increases in (MDA) and NO levels in the tissue homogenates. Bladder-GSH content is dropped by over $60 \%$ following CYCL injection. Bladder contractility, as measured by its responsiveness to $\mathrm{ACh}$, recorded a marked reduction. The isolated bladders exhibited such macroscopic changes as severe edema, inflammation and extravasation. The bladder weight increased as well. Histological changes were evident in the form of severe congestion, petechial hemorrhage and chronic inflammatory reaction in the lamina propria accompanied with desquamated epithelia. GA, a potential protective agent, produced an almost complete reversal of NO induction, lipid peroxidation or cellular GSH bladder contents in the GA + CYCL-treated group. Likewise, bladder inflammation and edema were reduced. Bladder rings showed a remarkable recovery in their responsiveness to ACh. Bladder histological examination showed a near normal configuration and structural integrity, with a significant reduction in inflammation and disappearance of focal erosions. These remarkable effects of GA may be

${ }^{*}$ Correspondence to: Adel R.A. Abd-Allah; Department of Pharmacology; College of Pharmacy; King Saud University; P.O. Box 2457; Riyadh 11451 Saudi Arabia; Tel.: +9661.4677263; Fax: +9661.4677200; Email:arabdallah@hotmail.com

Submitted: 04/11/09; Revised: 04/29/09; Accepted: 04/29/09

Previously published online as an Oxidative Medicine and Cellular Longevity E-publication:

http://www.landesbioscience.com/journals/oximed/article/8878 attributed to its ability to neutralize acrolein, the reactive metabolite of CYCL and/or the resultant reactive oxygen metabolites, through a scavenging action. GA may limit the cascading events of CYCL-induced damage, initiating a cytoprotective effect leading to structural and functional recovery of the bladder tissues.

\section{Introduction}

Cyclophosphamide (CYCL) is an established drug administered for the treatment of both malignant and nonmalignant conditions. CYCL is bioactivated to its reactive electrophilic metabolites through the cellular cytochrome P450 enzyme system, resulting in their ongoing production and slow accumulation in the plasma, causing severe cytotoxic effects in non-target tissues. ${ }^{1,2}$ Phosphoramide mustard and acrolein are the products of CYCL hydroxylation in the liver. ${ }^{1}$ Formation of acrolein, a highly reactive electrophilic $\alpha, \beta$-unsaturated aldehyde, is suggested to be the underlying cause of the toxicity of oxazaphosphorine cytotoxic agents such as CYCL. ${ }^{3,4}$ Acrolein has been implicated in the urinary bladder toxicity in humans ${ }^{5}$ as well as in animal model systems. ${ }^{4}$ Extensive tissue damage in the lungs as a result of CYCL treatment has also been documented. ${ }^{6,7}$ The most commonly reported CYCL-induced urological cytotoxicity is hemorrhagic cystitis. ${ }^{5,6,8}$ In patients receiving doses in excess of $200 \mathrm{mg} / \mathrm{kg}$ CYCL, a high incidence of hemorrhagic cystitis has been reported. ${ }^{6}$

Presence of the electrophilic metabolites of CYCL in urine and their contact with the bladder epithelium is the most likely the cause of the CYCL-induced bladder injury. Previous reports have suggested acrolein as the causal agent for bladder epithelial damage. ${ }^{4,6,9}$ Other factors such as cytokines, cyclooxygenase-2 (COX-2), and reactive oxygen species with other inflammatory mediators may contribute to the pathogenesis of CYCL-induced urotoxicity. Nitric oxide (NO) is suggested to play a significant role in the urinary tract injury associated with CYCL treatment. ${ }^{10}$ Oxidative stress damage manifested by a significant increase in the levels of malondialdehyde (MDA) and inhibition of the peroxidase and catalase enzymes ${ }^{8,11-13}$ presents another major cause of the tissue damage. CYCL-induced urotoxicity is the major limiting step in its clinical application despite of its potent antitumor activity. ${ }^{2}$ 
Cytotoxic side effects of potentially useful therapeutic agents on the non-target tissues is a major concern and has initiated extensive studies to identify chemical substances, natural or otherwise, helpful in reducing or eliminating the undesirable effects. A number of reports have elucidated the protective role of various compounds against the cytotoxicity of CYCL. Reactive nucleophilic compounds such as 2,6-Dithiopurine (DTP) have been shown to scavenge the electrophilic toxicants such as acrolein resulting from CYCL metabolism. ${ }^{4,15}$ Steroidal anti-inflammatory drugs like dexamethasone reduced bladder inflammation caused by CYCL. ${ }^{16}$ Agents such as cysteine, $\mathrm{N}$-acetylcysteine and mesna (2-mercaptoethane sulfonate) have been demonstrated to control the CYCL-induced bladder damage. ${ }^{12,17}$ Besides these, CYCL-induced oxidative stress damage was limited by the use of antioxidants such as ascorbic acid and stobadine. ${ }^{11,18}$ Moreover, our group has reported a remarkable protective effect of taurine against the CYCL-induced urotoxicity. ${ }^{19}$

In the genre of cytoprotective agents employed to mitigate the toxic effects of problem drugs, Gum Arabic (GA), a natural proteoglycan exudates from the stems of Acacia senegal, is emerging as a potential candidate for investigation. GA is a branched-chain, complex polysaccharide, either neutral or slightly acidic, found as a mixed calcium, magnesium and potassium salt of a polysaccharidic acid or that referred as Arabic gum acid. The backbone is composed of 1,3-linked b-D-galactopyranosyl units. The side chains are composed of two to five 1,3-linked b-D-galactopyranosyl units, joined to the main chain by 1,6-linkages. ${ }^{20-23}$ The structural characteristics of the gum arabic have been investigated once again by Mahendran et al. ${ }^{24}$ through monitoring the composition and physicochemical properties before and after treatment with proteolytic enzyme and various alkaline systems. The results revealed that GA macromolecules have a compact structure. Since, proteolytic enzyme of GA resulted in the arabinogalactan-protein component (AGP) with average molecular mass approximately $2 \times 10^{6} \mathrm{Da}$ to degrade, yielding material of molecular mass approximately $4 \times 10^{5} \mathrm{Da}$, whereas the bulk of the material corresponding to the protein-deficient arabinogalactan component with molecular mass $4 \times 10^{5}$ remained unaffected. Moreover, The gum arabic sample was deglycosylated by treatment with anhydrous hydrogen fluoride and revealed the presence of two putative core proteins of approximately $3 \times 10^{4}$ and approximately $5 \times 10^{3} \mathrm{Da}$, respectively, which correspond to proteins of approximately 250 and 45 amino acids in length. The study has concluded, therefore, that the enzyme did not fully hydrolyze all of the protein present and that the AGP component of gum arabic consists of carbohydrate blocks of approximately $4.5 \times 10^{4} \mathrm{Da}$ linked to a polypeptide chain consistent with the wattle blossom structure.

GA, a plant hydrocolloide, is extensively used in pharmaceutical and processed food industries as a stabilizing and texture-enhancing agent. Arab folk medicine has recognized the usefulness of GA in regulating the inflammation of intestinal mucosa and as an external soothing agent. ${ }^{23}$ Recent investigations on the application of GA as a cytoprotective agent have demonstrated its usefulness against a number of drugs. Oral administration of GA significantly palliated

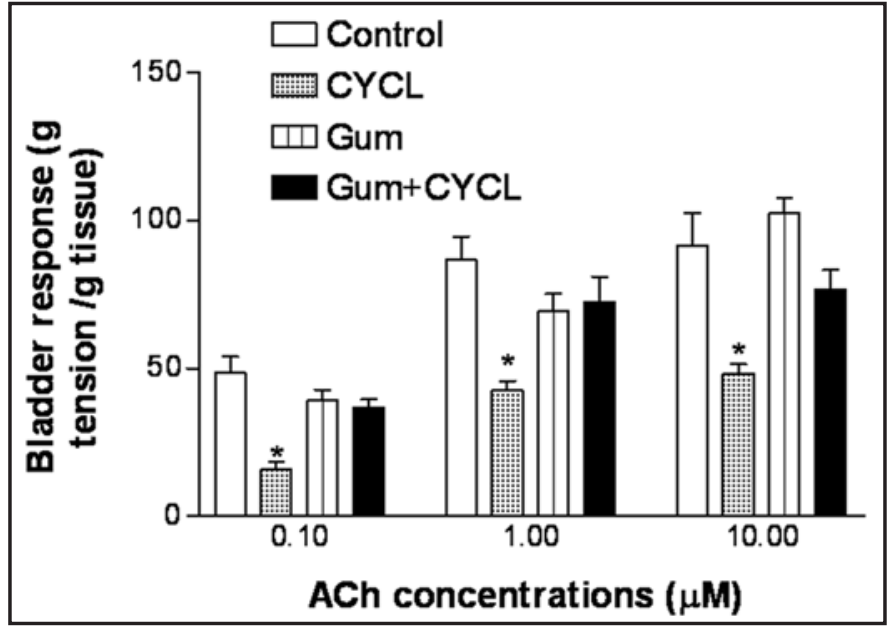

Figure 1. Effect of Gum Arabic on cyclophosphamide-induced changes in the urinary bladder contractile response to different concentrations of ACh. Data is presented as Mean \pm SEM (g tension/g tissue weight). GA was given in a dose of $7.5 \mathrm{~g} / \mathrm{kg} /$ day for 6 days in drinking water before and during the experimental period ( $24 \mathrm{~h}$ ) of $\mathrm{CYCL}$ that was given in a dose of $150 \mathrm{mg} / \mathrm{kg}$ i.p. CYCL induced a marked reduction in the contractile response, in a dose-response fashion, of the urinary bladder strips to Ach while GA significantly reserved this effect. Statistical analysis was done using one-way ANOVA followed by Tukey-Kramer as post-ANOVA test. *Significant difference from control group was accepted at $p<0.05$.

carbon tetrachloride induced hepatotoxicity in mice, ${ }^{22}$ gentamicin mediated nephrotoxicity in rats ${ }^{20}$ and cisplatin induced nephrotoxicity. ${ }^{21}$ Scavenging of nitric oxide by GA has been reported to limit the acetaminophen induced hepatotoxicity in mice. ${ }^{25}$ Other studies have documented the antioxidant properties of GA in a variety of animal model systems. ${ }^{26,27}$ Moreover, Abd-Allah et al. ${ }^{28}$ have reported that GA offers a strong antioxidant and radical scavenging activity in vivo and in vitro.

The present investigation is an attempt to elucidate the possible protective effects of GA on the urinary bladder tissue damage resulting from CYCL treatment in a rat model system. Bladder tissue responsiveness to Acetyl-choline (Ach), macroscopic characteristics such as extravasation and edema, biochemical parameters and histological changes has been studied to evaluate the protective effect of GA on the rat urinary bladder.

\section{Results}

Effect of GA on CYCL-induced changes in bladder contractile responsiveness of isolated urinary bladder rings to $\mathrm{ACh}$. Sensitivity of the isolated urinary bladder rings to various concentrations of acetylcholine (ACh) measured under control conditions produced minimum and maximum tension readings between $10^{-5}$ and $10^{-3} \mathrm{M}$ concentrations (Fig. 1) since higher concentrations showed the same maximal response. The average increments in the urinary bladder ring tension with ACh concentrations $10^{-5}, 10^{-4}$ and $10^{-3} \mathrm{M}$ for the control group were $48.5 \pm 5.39,86.8 \pm 7.86$ and $91.6 \pm 11.11 \mathrm{~g}$ tension $/ \mathrm{g}$ tissue, respectively. Treatment with CYCL significantly decreased the responsiveness of the rings to $\mathrm{ACh}$ as compared to that of the control group $(\mathrm{p}<0.05)$. 


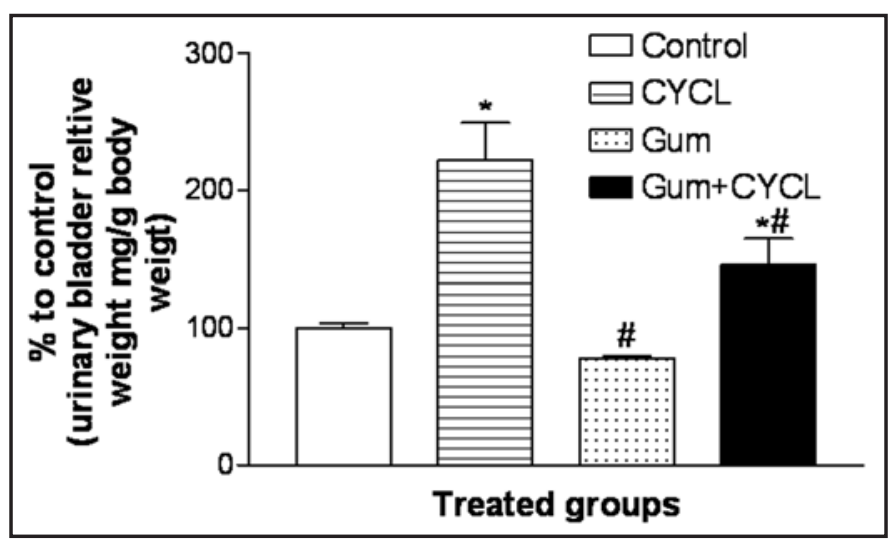

Figure 2. Effect of Gum Arabic on cyclophosphamide induced changes in urinary bladder relative weight. Data is presented as Mean \pm SEM (g tension/g tissue weight). GA was given in a dose of $7.5 \mathrm{~g} / \mathrm{kg} /$ day for 6 days in drinking water before and during the experimental period $(24 \mathrm{~h})$ of CYCL that was given in a dose of $150 \mathrm{mg} / \mathrm{kg}$ i.p. CYCL induced a marked increase in urinary bladder relative weight while GA significantly reserved this effect. Statistical analysis was done using one-way ANOVA followed by Tukey-Kramer as post-ANOVA test. * Significant difference from control group, \# and from CYCL-treated group was accepted at $p<0.05$.

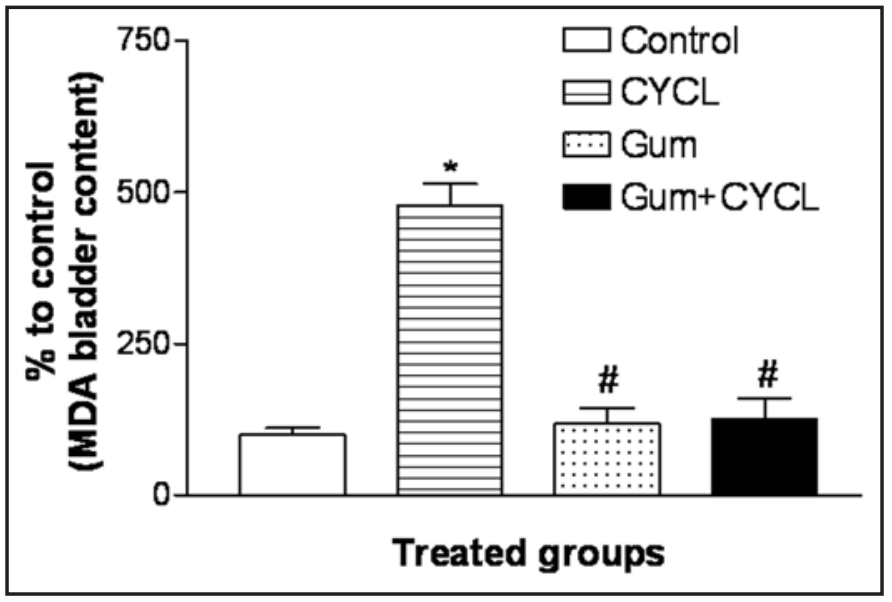

Figure 3. Effect of Gum Arabic and/or cyclophosphamide on the lipid peroxide content in rat urinary bladder homogenates. Data is presented as Mean \pm SEM (g tension/g tissue weight). GA was given in a dose of $7.5 \mathrm{~g} / \mathrm{kg} /$ day for 6 days in drinking water before and during the experimental period (24 h) of CYCL that was given in a dose of $150 \mathrm{mg} /$ kg i.p. $\mathrm{CYCL}$ induced a marked increase in urinary bladder MDA content while GA significantly prevented this effect. Statistical analysis was done using one-way ANOVA followed by Tukey-Kramer as post-ANOVA test. *Significant difference from control group, \# and from CYCL-treated group was accepted at $p<0.05$.

In the CYCL-treated group the mean increments in response to ACh were $15.95 \pm 2.49,42.85 \pm 2.97$ and $48.3 \pm 3.11 \mathrm{~g}$ tension/g tissue, respectively for the above concentrations. CYCL-treatment reduced the bladder response by $50-67 \%$ for the range of the measured concentrations. Pretreatment of the rats with GA alone did not affect the sensitivity in any appreciable fashion; however, pre-treatment with GA produced a remarkable recovery from the CYCL-induced loss of responsiveness. The bladder rings in the combination (GA + CYCL) group bounced back by 1.6- to 2.3-fold in their response to $\mathrm{ACh}$ exposure as compared to the CYCL-treated group indicating a significant protective effect of AG on the bladder against the CYCL-induced injury (Fig. 1).

Effect of GA on CYCL-induced changes in macroscopic parameters. Macroscopic observation of the urinary bladder for CYCL-induced tissue damage showed a significant increase in the bladder weight as percent of the body weight (Fig. 2). Gross vascular congestion resulting in edema and hemorrhage in the tissues had contributed to a 2.2-fold increase in the bladder weight of the CYCL-treated group over the control readings. Besides, the urothelial lining also exhibited a severe ulceration in this case. Oral supplementation of GA alone did not produce any noticeable difference in the weight as against the control. However, in the GA + CYCL-treated group a marked decrease in the vascular congestion could be seen as reflected by a 23\% drop in bladder weight (edema) as compared to the CYCL-treated group.

Effect of GA on CYCL-induced changes in lipid peroxides and glutathione contents. Bladder tissue homogenates of the various experimental groups were analyzed for malondialdehyde content as an indicator of lipid peroxidation (Fig. 3). A dramatic increase in MDA content in the bladder tissues of the CYCL-treated group (4.8-fold increase as compared to control and AG treated groups) was observed. This condition was equally dramatically reversed by AG in the case of the GA + CYCL combination group by bringing the MDA content back to the control level. Cellular GSH content in the urinary bladder homogenates of the CYCL-treated group, likewise, demonstrated a severe depletion (a reduction of $60 \%$ over the control, Fig. 4). A complete recovery of GSH content in the GA + CYCL treated group comparable to control and GA treatment levels indicates the same trend as seen in the case of reversal of MDA (Figs. 3 and 4).

Effect of GA on NO content (nitrate/nitrite) in the bladder tissues. The bladder tissue content of $\mathrm{NO}$ of normal rats was $0.32 \pm 0.1 \mathrm{nmol} / \mathrm{g}$ tissue. CYCL administration induced a marked increase in NO content reaching to about $180 \%$ of that of the control values (Fig. 5). Gum Arabic or GA + CYCL administration revealed no significant changes from that of control values (Fig. 5).

Effect of GA on histological changes in the bladder tissues. Histological examinations of the fixed tissue samples from CYCLtreated group exhibit severe edema and congestion of the urinary bladder (Fig. 6B and C) as compared to the control (Fig. 6A). Petechial hemorrhage and chronic inflammatory reaction in the lamina propria of the CYCL-treated bladder is obvious. In addition to the presence of proteinacious material in the lumen; erythrocytes, desquamative epithelium and plasma cells could also be seen (Fig. 6B). Focal erosion of the urinary bladder associated with acute and chronic inflammation in the case of CYCLtreatment could be observed with PAS stain (Fig. 6C), where edema of the adventitial tissue is also evident. Figure 6D presents a histological view of the AG + CYCL treated bladder where almost normal configuration and integrity of the tissues is visible. There is no sign of inflammation or lesions in this sample as against the 
CYCL-treated sample. GA treatment by itself did not produce any effect on the structural integrity of the bladder.

\section{Discussion}

Results of this study have once again conclusively established the adverse effects of CYCL on non-target tissues with particular reference to the hemorrhagic cystitis of the urinary bladder in an animal model system. CYCL-induced changes observed in the biochemical parameters are translated into a visible structural damage. Loss of bladder ring responsiveness to $\mathrm{ACh}$ and severe edema as reflected by the increased weight due to CYCL treatment, indicates gross changes in the structural integrity of the bladder. The underlying biochemical changes at the cellular level in terms of increased lipid peroxidation led to the macroscopic effects on the bladder epithelial lining. The argument that acrolein, an electophilic reactive metabolite of CYCL produces enormous oxidative stress on the target tissues coupled with other observations on the production of similar free radicals such as $\mathrm{NO}^{3,7,11,14}$ lend support to the observations of necrotic changes in the tissues. Since acrolein is not known to exist in the free form for extended periods, it is suggested that an acrolein metabolite or its conjugate may elicit the observed effects. ${ }^{8,29,30}$ The extent of the damage would be a function of both the concentration of the reactive species of the drug and the exposure time.

Increased lipid peroxidation (MDA) and decreased sulfhydryl (GSH) along with the increased NO bladder contents, in the present work, point to a greatly enhanced potential for oxidative stress on the urothelial lining. Ability of acrolein to deprive the cell of its natural defense (GSH) against the reactive oxygen species $^{31,32}$ or conjugates of acrolein directly inducing the formation of oxygen radicals. ${ }^{33}$ This support the suggestion that the outer membrane blebbing as a result of structural damage to the membranes ${ }^{34,35}$ could be an important cause of the compromised urothelial integrity as shown in our results. Gross histological changes manifested as severe inflammation and focal erosions of the bladder resulting from the urothelial cytotoxicity may therefore be associated with a corresponding loss in the bladder contractility (over 50\%). CYCL-induced bladder cystitis, therefore, appears to be a result of reactive oxygen species (ROS) overload or NO induction in the system ${ }^{36,37}$ triggering a cascade of events beginning with the membrane damage.

Several studies have documented the palliative effects of a range of substances on the CYCL-induced effects. ${ }^{12,13,15,19}$ GA has been shown to limit harmful side effects of several drugs previously. ${ }^{19-24}$ Our findings demonstrate the potential of Gum Arabic as a protective agent against the deleterious effects of CYCL. While on the one hand GA revealed a significant recovery in the bladder response to $\mathrm{ACh}$ and a reduction in the tissue edema, on the other hand it almost completely reversed the trends of oxidative damage to the tissues. Histological observations concur with these findings, where a near normal structural configuration of the bladder tissues is demonstrated upon GA supplementation.

GA has been demonstrated as an effective scavenger of ROS in several studies. ${ }^{20,22,24}$ Observations on dose dependent scavenging of superoxide radicals in vitro by $\mathrm{GA}^{19}$ and its high affinity to free radicals ${ }^{38,39}$ lend additional support to our suggestion that

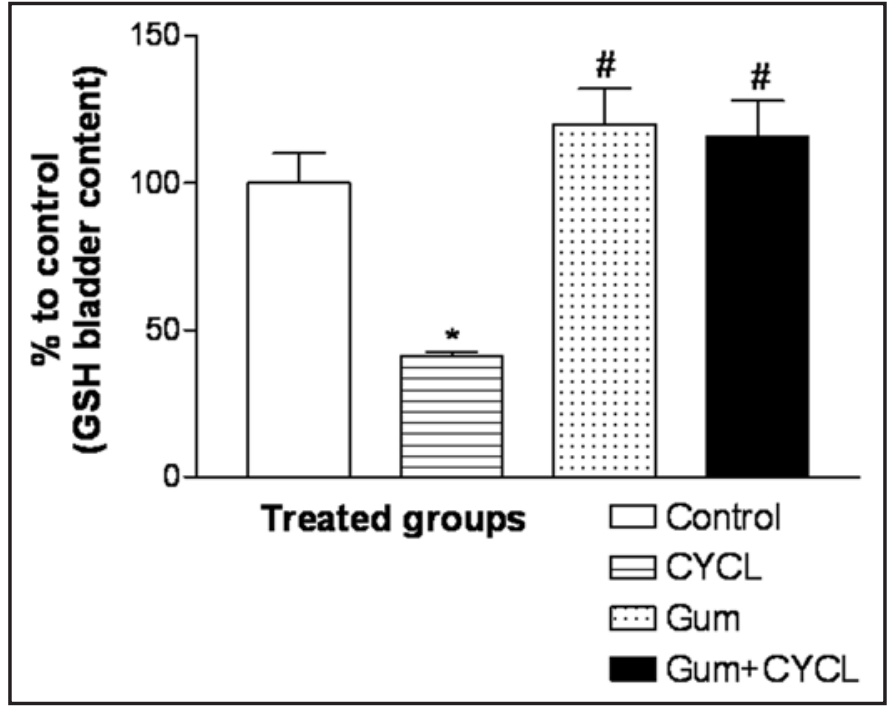

Figure 4. Effect of Gum Arabic and/or cyclophosphamide on the glutathione content in rat urinary bladder homogenates. Data is presented as Mean \pm SEM (g tension/g tissue weight). GA was given in a dose of $7.5 \mathrm{~g} / \mathrm{kg} /$ day for 6 days in drinking water before and during the experimental period (24 h) of CYCL that was given in a dose of $150 \mathrm{mg} / \mathrm{kg}$ i.p. CYCL induced a marked deplesion in urinary bladder GSH content while GA significantly restored GSH level. Statistical analysis was done using one-way ANOVA followed by Tukey-Kramer as post-ANOVA test. * Significant difference from control group, \# and from CYCL-treated group was accepted at $p<0.05$.

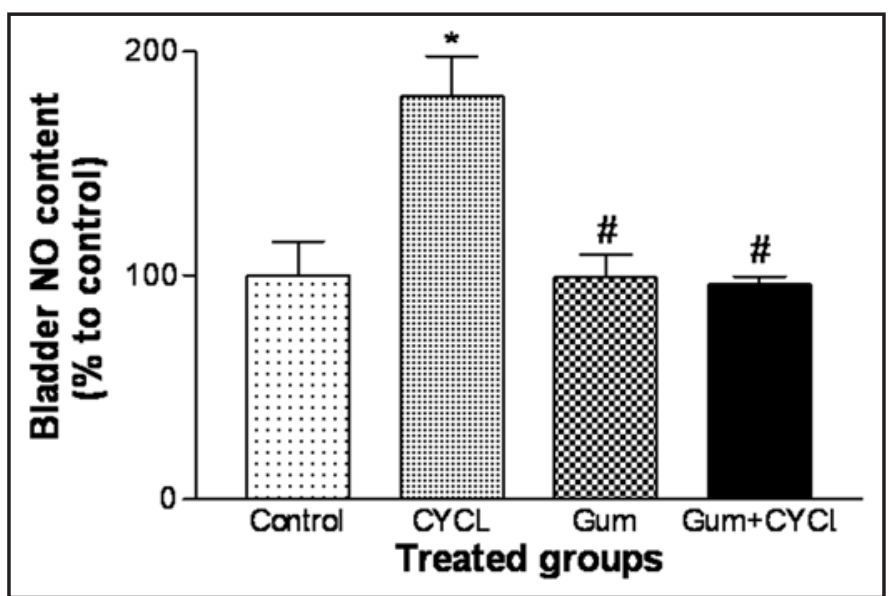

Figure 5. Effect of Gum Arabic and/or cyclophosphamide on the (NO) nitric oxide content in rat urinary bladder homogenates. Data is presented as Mean \pm SEM (g tension/g tissue weight). GA was given in a dose of $7.5 \mathrm{~g} / \mathrm{kg} /$ day for 6 days in drinking water before and during the experimental period (24 h) of CYCL that was given in a dose of $150 \mathrm{mg} / \mathrm{kg}$ i.p. CYCL induced a marked increase in urinary bladder NO content while GA significantly prevented its induction. Statistical analysis was done using one-way ANOVA followed by Tukey-Kramer as post-ANOVA test. * Significant difference from control group, \# and from CYCL-treated group was accepted at $p<0.05$.

GA probably acts primarily by neutralizing the ROS and relieving the urothelium from the oxidative stress to a large extent, if not completely. This in turn would result in a comparable reduction 


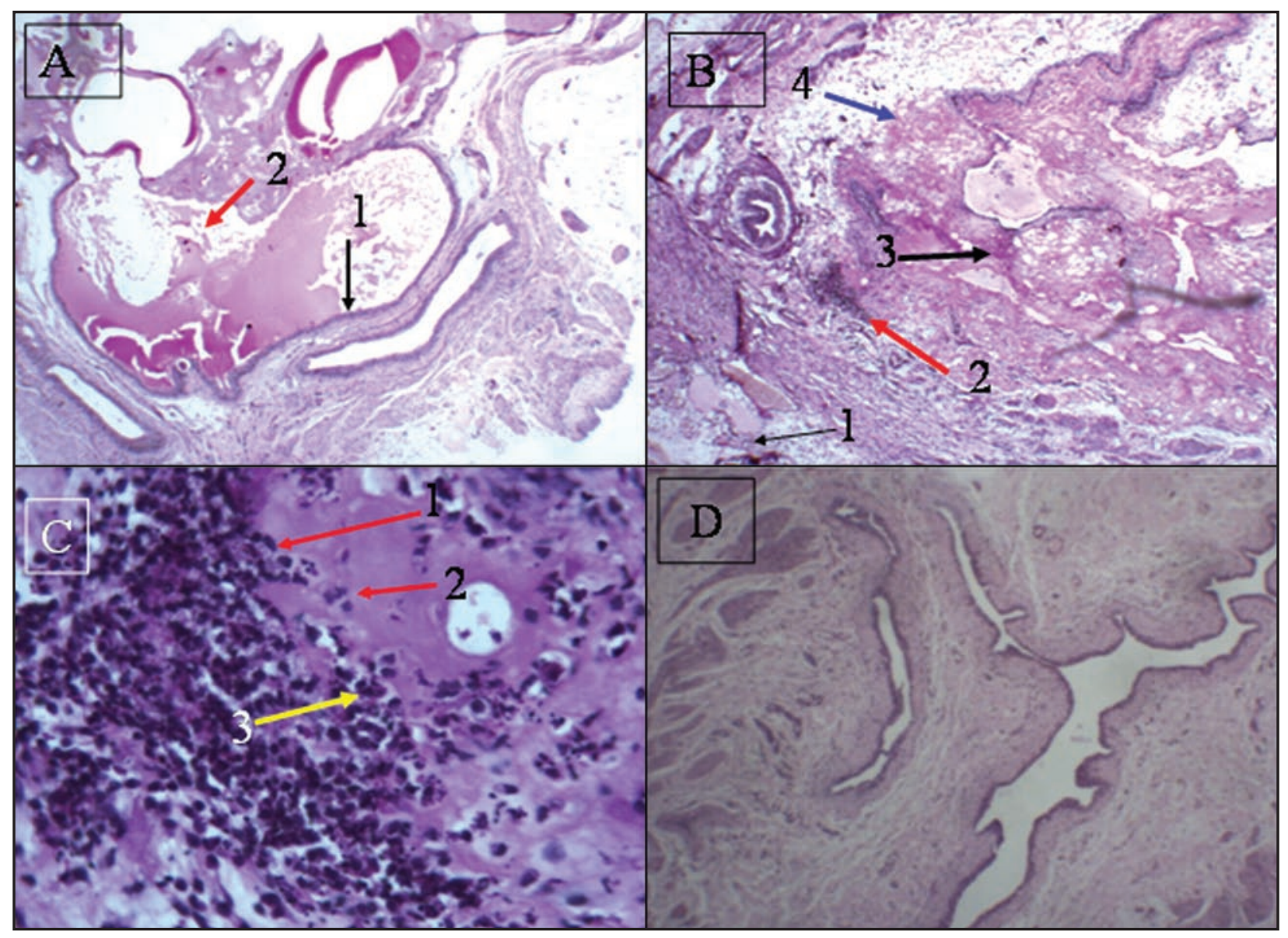

Figure 6. (A) Urinary bladder section from control animal showing a normal mucosa (arrow 1) and muscular coat with fluid in the lumen (arrow 2) (H\&E stain X100). (B) Urinary bladder section from CYCL-treated animal showing edema, congestion (arrow 1), petechial hemorrhage (arrow 2) and inflammation in the lamina propria (arrow 3) with protein aqueous material into the lumen as well as a desquamative epithelium (arrow 4) (H\&E stain X200). (C) Urinary bladder section from CYCL-treated animal showing edema, congestion, polymorphonuclear leukocytes and occasional erythroctes (arrow 1), lymphocytes (arrow 2) and plasma cell (arrow 3) infiltration with acute and chronic inflammation (PSA stain X400). (D) Urinary bladder section from GA followed by CYCL-treated animal showing mild residual nonspecific inflammation with almost normal structure (H\&E stain X200). GA was given in a dose of $7.5 \mathrm{~g} / \mathrm{kg} /$ day for 6 days in drinking water before and during the experimental period (24 h) of CYCL that was given in a dose of $150 \mathrm{mg} / \mathrm{kg}$ i.p. CYCL induced marked histological changes in rat urinary bladder that were almost completely prevented by GA.

in the bladder inflammation and associated with a significant decrease in NO content, an inflammatory mediator, with improvment of histological changes. Prevention of edema and a controlled petechial hemorrhage are bound to be reflected positively in the contractile efficiency of the bladder, especially when the loss of responsiveness is thought to be due to inflammation and edema. Our results clearly demonstrate a conspicuous relationship between the GA mediated reductions in the CYCL-induced lipid peroxidation, decreased edema and petechial hemorrhage and a visibly improved histological profile with a significant restoration of bladder contractility. Scavenging of the ROS and NO to limit the oxidative damage to the cell membranes appears to be the first line of action for GA in this case, which follows through with enhanced structural integrity resulting ultimately in a significant recovery of the bladder functionality. GA's efficiency as a potent cytoprotective agent may depend both on its qualitative and quantitative attributes and accessibility to the target tissues such as the intestine and kidney. ${ }^{23} \mathrm{GA}$ is absorbed from GIT following oral administration when it is given up to $10 \%$ of the diet. ${ }^{40}$ It is completely digested when given orally by rats and guinea-pigs and by humans. ${ }^{41}$ Moreover, when GA administered by humans it is excreted in urine by $5-32 \%$ of the administered dose as reported by Johnson and Newman. ${ }^{42}$ Experimental and clinical studies are conducted to GA in toxicological monograph by WHO, Food additives series 17 as a study to test for its use as a food additive. GA was evaluated for acceptance for daily intake for man by the joint of FAO/ WHO expert committee on food additive in 1969 that issued in 1970. GA showed many systemic effects following oral administration in experimental animals and in humans as shown by Booth et al. ${ }^{43}$ and Bachman and Zbinden. ${ }^{44}$ These data support the idea that GA may interact with ROS and/or acrolin in the urinary bladder in order to limit their damaging effects but the exact nature of its mode of action and conditions leading to its optimum effect need to be investigated in future studies particularly its effect on the NO synthase activity.

In summary, we conclude that Gum Arabic, a natural proteoglycan with known uses in the pharmaceutical and food industries is a potential candidate for a natural cytoprotective agent 
and that it primarily acts by mitigating the oxidative stress in the CYCL-induced urinary bladder cystitis in rats.

\section{Materials and Methods}

Chemicals. Cyclophosphamide (CYCL) (Endoxan-Asta) was purchased from ASTA Medica AG, (Frankfurt am Main, Germany). GA was purchased from Riedel-deHaen (D-3010 Seelze, Germany). Thiobarbituric acid (TBA) was a product of Fluka (Buchs, Switzerland). All the remaining chemicals were of the highest analytical grade commercially available.

Animals. Male Swiss albino rats, weighing 200-250 g were obtained from the Experimental Animal Care Center, College of Pharmacy, King Saud University, Riyadh, KSA. Animals were maintained under standard conditions of temperature $\left(24 \pm 1^{\circ} \mathrm{C}\right)$ and $55 \pm 5 \%$ relative humidity with regular $12 \mathrm{~h}$ light: $12 \mathrm{~h}$ dark cycle and allowed free access to standard laboratory food (Purina Chow, St. Louis, MO) and water.

Experimental protocol. Rats were randomly divided into four equal groups of 24 animals each. From each group six animals were used for bladder ring preparation and 18 animals for the biochemical analysis. The first group (control) rats were injected intraperitoneally with saline equal to the volume of the test solution. The second group received GA $(7.5 \mathrm{gm} / \mathrm{kg} /$ day $)$ alone in drinking water for 6 days, this dose has been adopted and preevaluated by previous studies. ${ }^{25-27}$ In the third experimental group, urinary bladder injury was induced by injecting animals with CYCL intraperitoneally at a dose of $150 \mathrm{mg} / \mathrm{kg}$ body weight and urinary bladder was examined $24 \mathrm{~h}$ later. This dose was chosen since it had been shown to produce severe urinary bladder toxicity. ${ }^{45}$ The fourth group received AG $(7.5 \mathrm{gm} / \mathrm{kg} /$ day, in drinking water for 6 days) then CYCL was injected. Gum Arabic treatment was maintained until the end of the experimental period $(24 \mathrm{~h}$ post-CYCL treatment). The experimental period of 24 hours was chosen based on previous studies ${ }^{19,28}$ which demonstrated that CYCL produced the maximum bladder injury during this period.

Following light ether anesthesia, the rats were sacrificed by cervical dislocation and the urinary bladders were quickly isolated, washed with saline, blotted dry on filter paper, examined macroscopically for detection of extravasations, congestion and weighted for detection of edema and then $10 \%(\mathrm{w} / \mathrm{v})$ homogenates of each sample was made from three pooled urinary bladders in ice cold saline using homogenizer (VWR Scientific, Danbury, CT). Due to the elasticity of the urinary bladder tissue, homogenization was run out, on ice, with different speeds until a homogenous tissue homogenate was obtained.

Determination of lipid peroxides in urinary bladder homogenates. Tissue levels of lipid peroxides were determined as thiobarbituric acid-reactive (TBARS) substances. ${ }^{46}$ Tissue homogenates were prepared as mentioned above, then $0.1 \mathrm{ml}$ homogenate was added to a tube containing $1.5 \mathrm{ml}$ acetic acid $(20 \%, \mathrm{pH} 3.5)$, $0.2 \mathrm{ml}$ sodium dodecyl-sulphate (SDS; $8.1 \%), 1.5 \mathrm{ml}$ TBA (0.8\%) and $0.7 \mathrm{ml}$ water; blanks were prepared by addition of water instead of homogenate. The tubes were mixed and incubated in a water path at $95^{\circ} \mathrm{C}$ for $60 \mathrm{~min}$ using glass balls as condensers. Then, all the tubes were cooled to the room temperature and centrifuged at $1,000 \mathrm{~g}$ for $10 \mathrm{~min}$. The absorbance of the supernatant was measured photometrical at $532 \mathrm{~nm}$ and concentrations, expressed as nmol malondialdehyde (MDA)/g tissue, were determined against a standard curve of 1,1,3,3,tetraethoxypropane (Sigma chemical CO, St. Louis, MO).

Determination of GSH content in urinary bladder tissue. Tissue levels of acid-soluble thiols, mainly reduced glutathione (GSH), were determined colorimetrically at $412 \mathrm{~nm} .{ }^{47}$ Briefly, 0.5 $\mathrm{ml}$ of previously prepared homogenate was added to $0.5 \mathrm{ml}$ of $5 \%$ trichloroacetic acid and after centrifugation at $750 \mathrm{~g}$ for $5 \mathrm{~min}$., the supernatant $(200 \mu \mathrm{l})$ was added to a tube containing $1,750 \mu \mathrm{l}$ of $0.1 \mathrm{M}$ Potassium phosphate buffer, $\mathrm{pH}$ 8) and $50 \mu \mathrm{l}$ DTNB reagent. The tubes were mixed and the developed yellow color was measured against standard curve of reduced glutathione. Protein thilos (protein- $\mathrm{SH}$ ) were expressed as $\mu \mathrm{mol} / \mathrm{g}$ tissue.

Determination of nitric oxide, NO, (as nitrate/nitrite) in bladder homogenates. ${ }^{48}$ From the previously prepared bladder homogenates, $0.5 \mathrm{ml}$ was added to $0.5 \mathrm{ml}$ of absolute ethanol then centrifuged at $4,000 \mathrm{rpm}$ for $10 \mathrm{~min}$. Then to $300 \mu \mathrm{l}$ of the supernatant $300 \mu \mathrm{l}$ of vanadium chloride $(\mathrm{VCl} 3,0.8 \%$ in $1 \mathrm{M} \mathrm{HCl})$ was added. Then $300 \mu \mathrm{l}$ of a mixture of Griess 1 and 2 reagents $1: 1$, and $100 \mu \mathrm{l}$ of their solvents were added. Griess 1 reagent is composed of $\mathrm{N}$-(1-naphthyl)-ethylenediamine (NEDD, $0.1 \%$ in distilled water) and Griess 2 is composed of sulfanilamide, $2 \%$ in $5 \% \mathrm{HCl}$. The mixture was left at room temperature 30-35 min then the color was measured spectrophotometrically at 540 against blank. Concentrations of $\mathrm{NO}$ were determined from a standard curve of different concentration of sodium nitrite. $\mathrm{NO}$ equivalent concentrations were calculated as $\mathrm{nmol} / \mathrm{g}$ tissue.

Preparation of the urinary bladder rings. After animals had been sacrificed, the lower abdomen was opened and the bladder exposed. The connective tissue and accompanying blood vessels were cut away and the bladder was cut into rings and placed in warm physiological salt solution (PSS). The composition of the PSS $^{31}$ (in g/L): $\mathrm{NaCl}, 6.9 ; \mathrm{Na}_{\mathrm{HCO}_{3}}, 2.1 ; \mathrm{KCl}, 0.35 ; \mathrm{MgSO}_{4}$, $0.15 ; \mathrm{KH}_{2} \mathrm{PO}_{4}, 0.16, \mathrm{CaCl}_{2}, 0.28$ and glucose, 2.0. Rings were mounted horizontally between a clamp and a force transducer for measurement of isometric tension using a Statham transducer (Gould Instrument, Cleveland, $\mathrm{OH}$ ) in an organ bath filled with $10 \mathrm{ml}$ of the PSS at a temperature of $37^{\circ} \mathrm{C}$ and gassed with $95 \% \mathrm{O}_{2}-5 \% \mathrm{CO}_{2}$.

Rings were allowed to equilibrate for $30 \mathrm{~min}$ prior to experiment under a resting load of $1 \mathrm{~g} .{ }^{49}$ During this time, the bath solution was replaced every $5 \mathrm{~min}$. Isometric tension was recorded by means of a Stathman transducer connected to a physiograph (Narco Bio-system, Houston, TX).

A concentration-response curve to acetylcholine (ACh) was constructed. Rings were exposed to different concentrations of Ach, ranging from $10^{-8}$ to $10^{-2} \mathrm{M}$, in a non-cumulative manner. Exposure to a dose of ACh was maintained until the maximal response to that concentration was reached. The rings were then washed repeatedly with several changes of PSS and allowed to return to baseline before the addition of the next $\mathrm{ACh}$ concentration.

Histopathological examination. Urinary bladders were collected, as detailed above, and fixed in $10 \%$ formalin in 
phosphate buffer saline, ( $\mathrm{pH} 0.7$ ) for $24 \mathrm{~h}$ at room temperature. Then, tissues were embedded in paraffin wax and sections were cut at $5 \mu \mathrm{m}$ thickness and stained with haematoxylin-eosin or periodic acid-Schiff (PAS) stains using routine procedures. A histopathologist, who was unaware of the treatments, examined the coded slides using a light microscope and recorded and photographed the histopathological lesions.

Statistical analysis. Data are expressed as (means \pm SEM). Statistical comparison between different groups were performed using one way analysis of variance (ANOVA) followed by TukeyKramer multiple comparisons test to judge difference between groups. Significance was accepted at $\mathrm{p}<0.05$.

\section{References}

1. Moore MJ. Clinical pharmacokinetics of cyclophosphamide. Clin Pharmacokinet 1991; 20:194-208.

2. Hengstler JG, Hengst A, Fuchs J, Tanner B, Phol J, Oesch F. Induction of DNA crosslinks and DNA strand lesions by cyclophosphamide after activation by cytochrome P450 2B1. Mutat Res 1997; 373:215-23.

3. Levy L, Harris R. Effect of N-acetylcysteine on some aspects of cyclophosphamide induced toxicity and immuno-suppression. Biochem Pharmacol 1977; 26:1015-20.

4. Cox Pj. Cyclophosphamide-cystitis identification of acrolein as the causative agent. Biochem Pharmacol 1977; 28:2045-9.

5. Austin HA, Klippel JH, Balow JE, Le Riche NGH, Steinberg AD, Plotz PH, Decker JL. Therapy of lupus nephrits-controlled trial of prednisone and cytotoxic drugs. N Eng J Med 1986; 314:614-9.

6. Fraiser LH, Kanekal S, Kehrer JP. Cyclophosphamide toxicity characterizing and avoiding problem. Drugs 1991; 42:781-95.

7. Takamoto S, Sakura N, Namera A, Yashiki M. Monitoring of urinary acrolein concentration in patients receiving cyclophosphamide and ifosphamide. J Chromatogr B Analyt Technol Biomed Life Sci 2004; 806:59-63.

8. Fraiser LH, Kehrer JP. Murine strain differences in metabolism and bladder toxicity of cyclophosphamide. Toxicology 1992; 7:255-72.

9. Philips FS, Sternberg SS, Cronin AP, Vidal PM. Cyclophosphamide and urinary bladder toxicity. Cancer Res 1961; 21:1577-89.

10. Alfieri AB, Cubeddu LX. Nitric oxide and NK1-Tachkinin receptors in cyclophosphamide-induced cystitis in rats. J Pharmacol Exper Ther 2000; 295:824-9.

11. Das UB, Mallick M, Debnath JM, Ghosh D. Protective effect of ascorbic acid on cyclophosphamide-induced testicular gametogenic and androgenic disorders in male rats. Asian J Androl 2002; 4:201-7.

12. Gurtoo HL, Hipkens JH, Sharma SD. Role of glutathione in the metabolism dependent toxicity and chemotherapy of cyclophosphamide. Cancer Res 1981; 41:3584-91.

13. Lee FYF. Glutathione diminishes the anti-tumor activity of 4-hydroperoxycyclophosphamide by stabilizing its spontaneous breakdown to alkylating metabolites. Br J Cancer 1991; 63:45-50.

14. Qing WG, Powell KL, MacLeod MC. Kinetics of the reaction of a potential chemopreventive agent, 2,6-dithiopurine and its major metabolite, 2,6-dithiouric acid, with multiple classes of electrophilic toxicants. Chem Res Toxicol 1996; 9:1298-304.

15. Datta K, Chin A, Ahmed T, Qing WG, Powell KL, Simhambhatla P, et al. Mixed effects of 2,6-dithiopurine against cyclophosphamide mediated bladder and lung toxicity in mice. Toxicology 1998; 125:1-11.

16. Lecci A, Meini S, Tramontana M, Giuliani S, Criscuoli M, Maggi CA. Kinin $B_{1}$ receptor-mediated motor responses in normal or inflamed rat urinary bladder in vivo. Regulatory Peptides 1999; 80:41-7.

17. Brock N, Pohl J. Prevention of urotoxic side effects by regional detoxification with increased selectivity of oxazophosphorine cytostatics. IARC Sci Publ 1986; 78:269-79.

18. Navarova J, Ujhazy E, Dubovicky M. Protective effect of the antioxidant stobadine against cyclophosphamide and irradiation induced oxidative stress. Gen Physiol Biophys 1999; 18:112-9.

19. Abd-Allah AR, Gado AM, Al-Majed AA, Al-Yahya AA, Al-Shabanah OA. Protective effect of Taurine against cyclophosphamide induced urinary bladder toxicity in rats. Clin Exper Pharmacol Physiol 2005; 31:167-72.

20. Al-Majed AA, Mostafa AM, Al-Rikabi AC, Al-Shabanah OA. Protective effects of oral arabic gum administration on gentamicin-induced nephrotoxicity in rats. Pharmacol Res 2002; 46:445-51.

21. Al-Majed AA, Abd-Allah ARA, Al-Rikabi AC, Al-Shabanah OA, Mostafa AM. Effect of oral administration of Arabic gum on Cisplatin-induced nephrotoxicity in rats. J Biochem Mol Toxicol 2003; 17:146-53.

22. Al-Majed AA. Oral Arabic gum administration prevents carbon tetrachloride-induced hepatotoxicity in mice: A possible mechanism of protection. Res Commun Pharmacol Toxicol 2003; 8:35-48.
23. Ali BH, Ziada A, Blunden G. Biological effects of Gum Arabic: A review of some recent research. Food Chem Toxicol 2009; 47:1-8.

24. Mahendran T, Williams PA, Phillips GO, Al-Assaf S, Baldwin TC. New insights into the structural characteristics of the arabinogalactan-protein (AGP) fraction of gum arabic. J Agric Food Chem 2008; 56:9269-76.

25. Gamal El-din AM, Mostafa AM, Al-Shabanah OA, Al-Bekairi AM, Nagi MN. Protective effect of arabic gum against acetaminophen-induced hepatotoxicity in mice. Pharmacol Res 2003; 48:631-5.

26. Rehman KU, Codipilly CN, Wapnir RA. Modulation of small intestinal nitric oxide synthase by gum arabic. Exp Biol Med 2004; 229:895-901.

27. Ali BH. Does gum arabic have an antioxidant action in rat kidney? Ren Fail 2004; 26:1-3.

28. Abd-Allah AR, Al-Majed AA, Mostafa AM, Al-Shabanah OA, Din AG, Nagi MN. Protective effect of arabic gum against cardiotoxicity induced by doxorubicin in mice: a possible mechanism of protection. J Biochem Mol Toxicol 2002; 16:254-9.

29. Ramu K, Fraiser LH, Mamiya B, Ahmed T, Kehrer JP. Acrolein mercapturates: synthesis, characterization and assessment of their role in the bladder toxicity of cyclophosphamide. Chem Res Toxicol 1995; 8:515-24.

30. Ramu K, Perry CS, Ahmed T, Pakenham G, Kehrer JP. Studies on the basis for the toxicity of acrolein mercapturates. Toxicol Appl Pharmacol 1996; 140:487-98.

31. Arumugam N, Sivakumar V, Thanislass J, Pillai KS, Devaraj SN, Devaraj H. Acute pulmonary toxicity of acrolein in rats-underlying mechanism. Toxicol Lett 1999; 104:189-94.

32. Arumugam N, Thanislass J, Ragunath K, Niranjali Devaraj S, Devaraj H. Acroleininduced toxicicy-defective mitochondrial function as a possible mechanism. Arch Environ Contam Toxicol 1999; 36:373-6.

33. Adams JD Jr, Klaidman LK. Acrolein-induced oxygen radical formation. Free Radic Biol Med 1993; 15:187-93.

34. Bullock G, Tang C, Tourkina E, Ibrado AM, Lutzky J, Huang Y, et al. Effect of combined treatment with interleukin-3 and interleukin-6 on 4-hydroperoxycyclophosphamide-induced programmed cell death of apoptosis in human myeloid leukemia cells. Exp Hematol 1993; 21:1640-7.

35. Hengstler JG, Hengst A, Fuchs J, Tanner B, Phol J, Oesch F. Induction of DNA crosslinks and DNA strand lesions by cyclophosphamide after activation by cytochrome P450 2B1. Mutat Res 1997; 373:215-23.

36. Inci K, Ismailoglu UB, Sahin A, Sungur A, Sahin-Erdemli I. The effect of inflammation on rat urinary bladder-dependent relaxation in coaxial bioassay system. Naunyn Schmiedebergs Arch Pharmacol 2003; 367:457-552.

37. Manesh C, Kuttan G. Alleviation of cyclophosphamide-induced urotoxicity by naturally occurring sulphur compounds. J Exp Clin Cancer Res 2002; 21:509-17.

38. Oter S, Korkmaz A, Oztas E, Yildirim I, Topal T, Bikgic H. Inducible nitric oxide synthase inhibition in cyclophosphamide induced hemorrhagic cystitis in rats. Ureol Res 2004; 32:185-9.

39. Rehman K, Wingertzahn MA, Harper RG, Wapnir RA. Proabsorptive action of gum Arabic: regulation of nitric oxide metabolism in the basolateral potassium channel of the small intestine. J Ped Gast Nut 2001; 32:529-33.

40. O'Dell BL, Morris ER, Pickett EE, Hogan AG. Diet composition and mineral balance in guinea pigs. J Nutrition 1957; 63:65-77.

41. Shue GM, Douglass CD, Friedman I. Nutritional studies of complex carbohydrates. Federation proceedings 1962; 21:91-5.

42. Johnson JB, Newman LH. Intravenous injection of acacia. Arch Intern Med 1945; 76:167-71.

43. Booth AN, Elvehjem CA, Hart EB. The importance of bulk in nutrition of guinea pig. J Nutr 1949; 37:263-8.

44. Bachmann E, Zbinden G. Biochemical effects of chronically administered suspended agents on mitochondrial metabolism and hepatic mixed function oxidase in rats, mice and hamster. Arch Toxicol Suppl 1978; 1:183-7.

45. Xu X, Malave A. Protective effect of Berberine on cyclophosphamide hemorrhagic cystitis in rats. Pharmacol Toxicol 2001; 88:232-7.

46. Ohkawa $\mathrm{H}$, Ohish N, Yagi K. Assay for lipid peroxides in animal tissues by thiobarbituric acid. Anal Biochem 1979; 95:351-8.

47. Ellman GL. Tissue sulfahydryl groups. Arch Biochem Biophys 1959; 82:70-7.

48. Ozawa H, Chancellor MB, Jung SY, Yokoyama T, Fraser MO, Yu Y, et al. Effect of intravesical nitric oxide therapy on cyclophosphamide-induced cystitis. J Urol 1999; 162:2211-6.

49. Mostafa AM, Nagi MN, Al-Shabanah OA, El-Kashef HA. Effect of amino-guanidine and melatonin on the response of isolated urinary bladder to acetylcholine in normal and diabetic rats. Med Sci Res 2000; 28:33-7. 


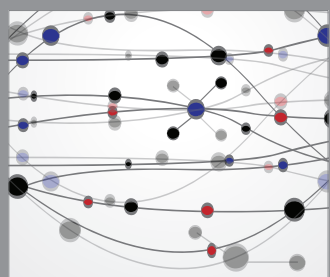

The Scientific World Journal
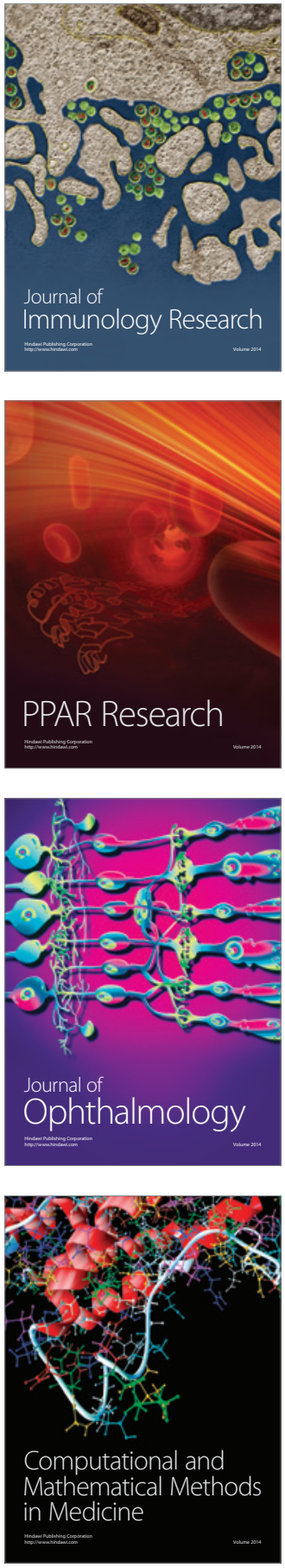

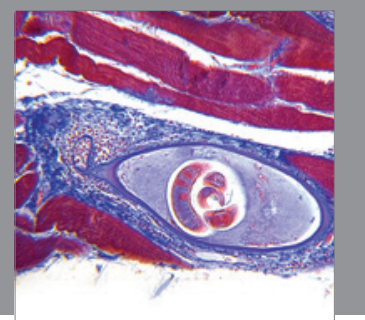

Gastroenterology

Research and Practice
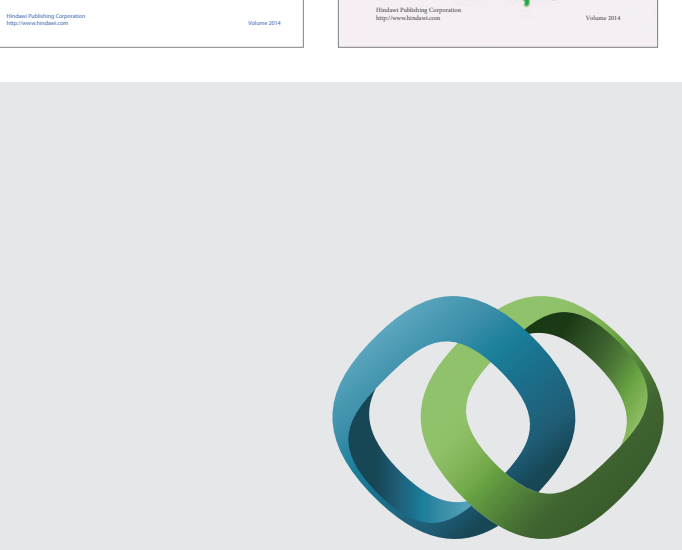

\section{Hindawi}

Submit your manuscripts at

http://www.hindawi.com
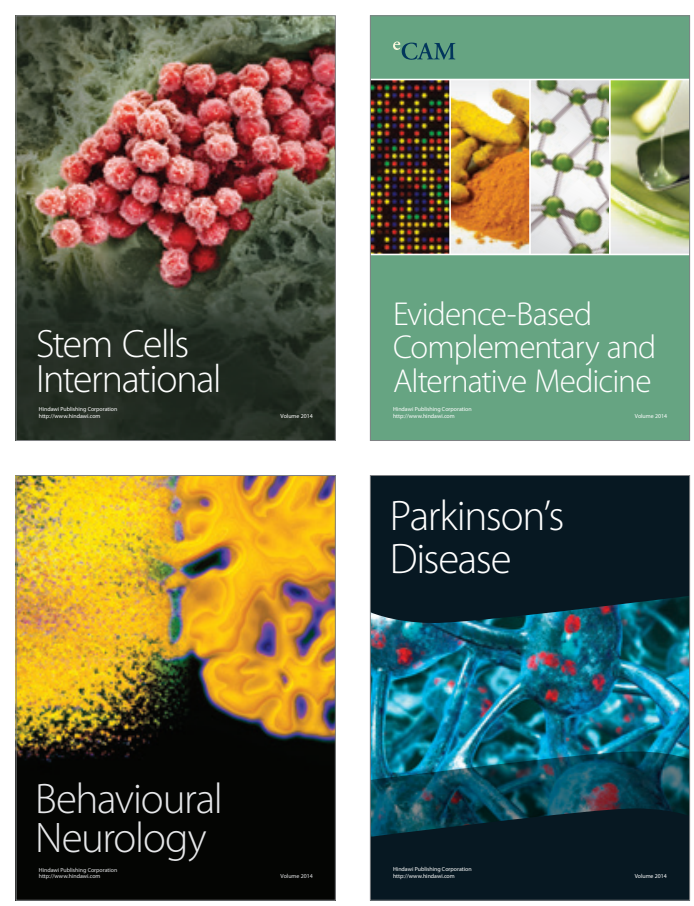

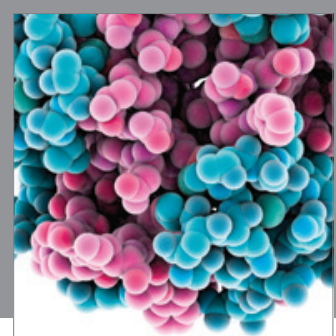

Journal of
Diabetes Research

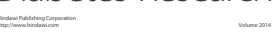

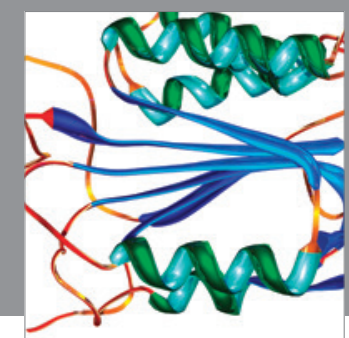

Disease Markers
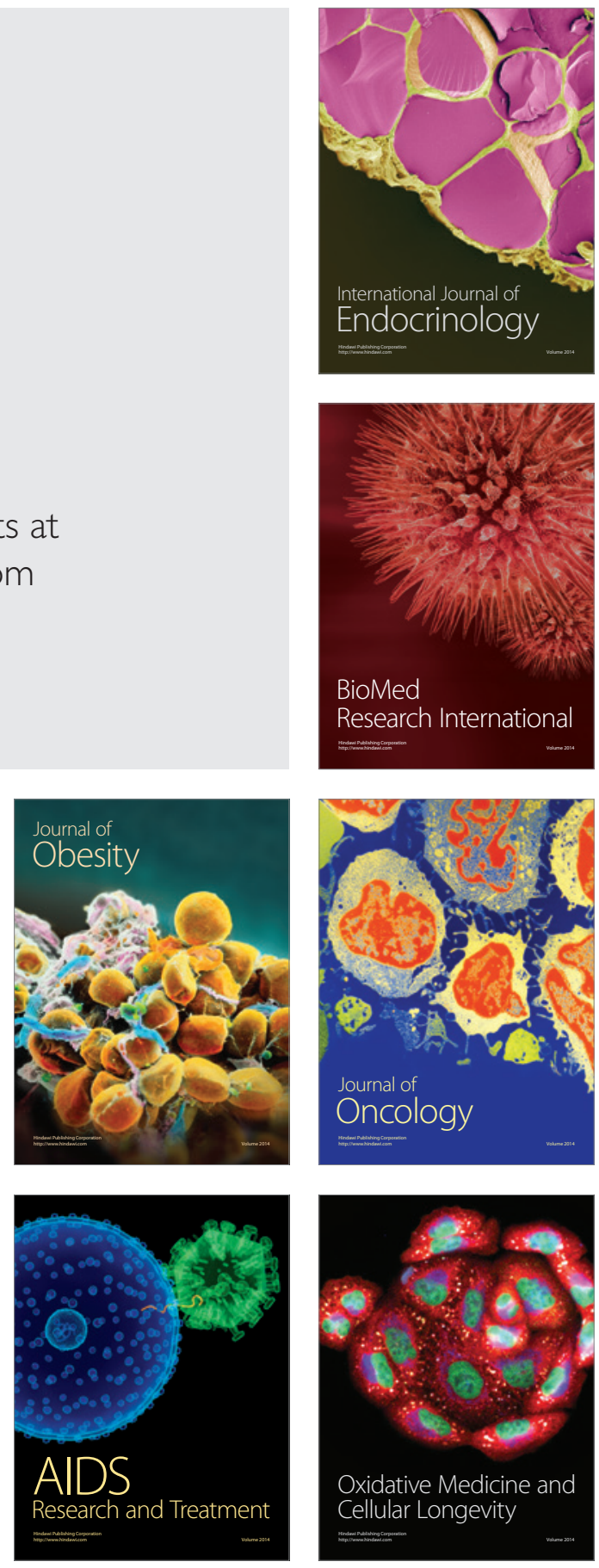